\title{
Reformas pró-mercado, rigidez constitucional e revisão judicial: Brasil, Argentina e Uruguai em perspectiva comparada
}

Izabela Moreira Corrêa e Vanúzia Gonçalves Amaral

\section{Introdução}

\section{Reformas pró-mercado como políticas de mudança institucional}

Estudar as reformas pró-mercado como políticas de mudanças institucionais ${ }^{1}$ facilita a compreensão de diversos fatores: os atores políticos envolvidos e suas preferências com relação às issue areas das políticas; as instituições que constrangem a implementação de um novo arranjo institucional; e o impacto da conjuntura política, social e econômica para a formação de preferências e de jogos políticos. Estudos em perspectiva comparada permitem evidenciar que a mobilização de atores políticos com recursos de poder idênticos em contextos institucionais e conjunturais distintos interferem nos resultados das políticas. Essa diferença ocorre porque arranjos institucionais distintos possibilitam maior - ou menor - atuação de veto players ${ }^{2}$.

Este artigo aborda a dispersão de recursos de poder dos cidadãos e dos Poderes Executivo, Legislativo e Judiciário para viabilizar a implementação de 
políticas de reforma pró-mercado no Brasil, na Argentina e no Uruguai. Para tal, trataremos da flexibilidade constitucional, da dinâmica de formação das leis e da presença ou ausência de revisão judicial. As reformas previdenciárias serão utilizadas como casos empíricos de reforma pró-mercado, para exemplificar a hipótese subjacente a este artigo: quanto mais rígida a Constituição mais bem desenhado tem de ser o jogo político para viabilização de implementação da política. Ressalte-se que cada um dos países aqui estudados (Brasil, Argentina e Uruguai) iniciou suas reformas em tempos distintos, em meio a graves crises econômicas e à forte mobilização social - sabe-se que, por exemplo, reformas no sistema previdenciário alteram diversos padrões de benefícios.

Em síntese, esses países passaram por reformas estruturais nos anos 80 e 90, reformaram seus regimes de previdência social, ora convergindo, ora divergindo em modelos de previdência e especialmente em jogos políticos. O timing das reformas e seus resultados foram e são distintos. Os três países aqui analisados têm, em maior ou menor grau, o problema da desigualdade estrutural e seus Poderes Executivos possuíam também graus diferenciados de liberdade no plano de execução de suas políticas econômicas. Na conclusão, chamaremos atenção também aos metajogos trazidos pelas mudanças institucionais nas reformas pró-mercado, ou seja, situações em que o conteúdo da política não trata somente das issue areas da política, mas também das regras pela qual determinada política poderá ser modificada ou regulamentada em momento posterior.

\section{Democracia representativa e reformas pró-mercado}

Tanto o welfare state, que vigorou plenamente em alguns países europeus, quanto os Estados desenvolvimentistas, que predominaram na América Latina especialmente no Brasil -, apresentam transformações desde os anos 1960 e 1970. Estados europeus e os latino-americanos passaram por crises de diferentes causas. Ao welfare state atribui-se um excesso de demandas que as políticas do bem-estar teriam causado aos Estados. Essas demandas teriam saturado esse sistema político, e o crescimento geométrico e incontrolável dos gastos sociais não foi acompanhado pela capacidade de arrecadação do Estado. A crise do Estado nos países latino-americanos é debitada à sua própria forma de crescimento: os Estados desenvolvimentistas, que se caracterizam por forte intervenção na economia e presença atuante no setor produtivo, chegaram a enorme déficit e a total desequilíbrio fiscal na década de 1980. Para equilibrar suas contas, esses Estados recorreram a empréstimos junto a organismos internacionais, como o FMI, aumentaram seu endividamento externo e interno e começaram a sofrer com o descontrole da inflação e do desemprego ${ }^{3}$. $\mathrm{E}$, neste contexto, as chamadas reformas pró-mercado ganharam força na agenda política dos países latino-americanos.

Como afirma Boschi (2004, p.1), está em curso, no Brasil, uma “[...] conjuntura de transição na qual, embora os rumos tenham sido definidos pela tentativa de ruptura com as características estruturais e o padrão de relacionamento entre os setores público e o privado que caracterizavam o período anterior, não se chegou ainda a uma síntese institucional mais permanente". O autor argumenta que essa transição constitui-se fundamentalmente na "redefinição das modalidades de coordenação econômica”, que, antes centralizadas no Estado, passam a ser 
coordenadas pelo mercado, buscando neutralizar fatores políticos. Embora nessa análise o autor trate especificamente do caso brasileiro, ao abordar temas de inovação institucional, de alteração do padrão de intervencionismo estatal e de implementação das reformas neoliberais especialmente nos anos 1990 -, pode-se dizer que as reformas na América Latina seguiram um padrão semelhante ao brasileiro, com exceção do Chile, que iniciou suas reformas em regime de governo autoritário.

Segundo Anastasia e Melo (obra no prelo), "O fato de que as democracias contemporâneas são regimes representativos, não nos deve fazer esquecer que democracia e representação são fenômenos analiticamente distintos". Democracia envolve, acima de tudo, a problematização da constituição dos fins (REIs, 1995; Manin, 1995; Diniz, 1996), ou seja, os procedimentos utilizados para alcançar determinados fins. Já a representação, segundo Manin (1995), é a forma política mais adequada às complexas e heterogêneas sociedades modernas. Nesse sentido, as assembléias (parlamentos ou congressos) tornam-se a arena política de debate para a tomada de decisões acerca de assuntos de interesse público, por meio dos representantes do povo.

As mudanças institucionais chamadas de reformas pró-mercado representam mudanças estruturais para o funcionamento do Estado. Dessa forma, muitas das mudanças decorrentes dessas reformas só podem ser implementadas por alterações constitucionais. Sendo a Constituição a lei superior de um país e sendo as políticas de reformas para o mercado as reformas constitucionais, procura-se abordar, neste artigo, a dispersão de poderes no concernente às reformas constitucionais.
Lijphart (2003), em Modelos de democracia, ao discutir acerca da concentração ou partilha no Poder Executivo, contrasta o princípio majoritário de "[...] concentração de poder nas mãos da maioria" e o princípio "consensual de ampla participação no poder". Ao contrário da estabilidade defendida em favor da democracia majoritária, Lijphart (2003) argumenta que as democracias de consenso apresentam melhor desempenho no concernente à

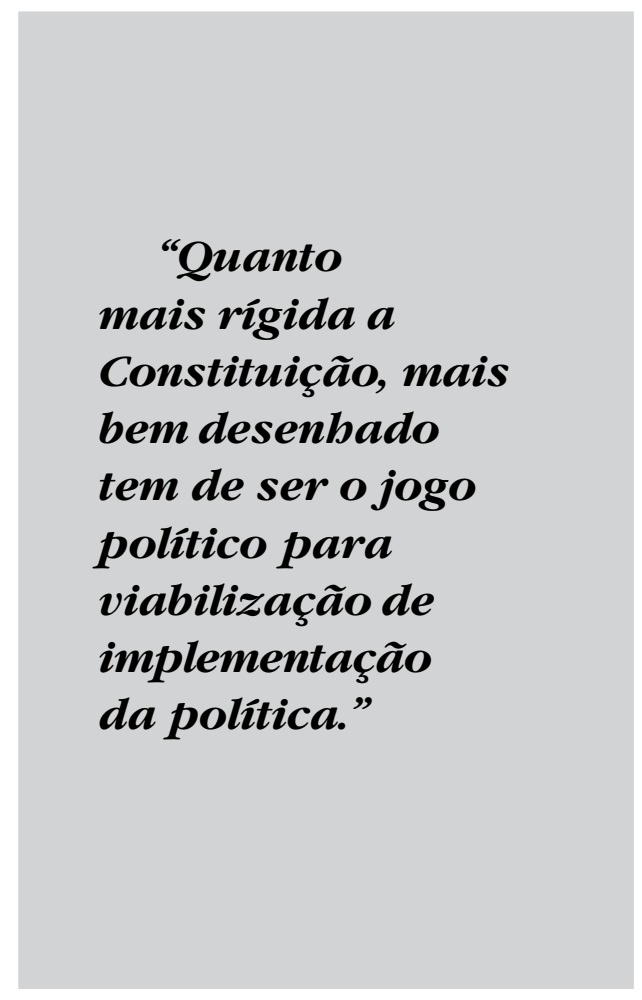

qualidade e às representatividades democráticas. A principal hipótese é a de que, em sociedades heterogêneas, a prevalência da maioria - na qual o vencedor leva tudo significaria a exclusão da participação dos grupos perdedores nos processos decisórios, acarretando um déficit muito grande para a democracia do país.

Sobre gabinetes presidencialistas forma de governo dos três países aqui 
estudados -, o autor ressalta as diferenças em relação aos gabinetes parlamentaristas. No presidencialismo, "Os presidentes são eleitos por um mandato fixo e nem eles, nem os gabinetes que indicam, dependem da confiança da legislatura para sua sobrevivência no cargo" (LIJPHART, 2003, p.129), todavia o Executivo necessita de maioria legislativa para conseguir implementar as propostas legislativas do presidente. $\mathrm{O}$ jogo político, entretanto, não se dá estritamente entre Executivo e Legislativo, dado que, em alguns países, o Judiciário tem forte atuação. $\mathrm{O}$ objetivo a que se propõe este artigo, ao se considerarem as preferências intensas dos atores com relação às políticas de reforma pró-mercado, é estudar a flexibilidade constitucional de três países do Cone Sul para a implementação dessas políticas. Procuraremos enfatizar se a Constituição representa a "[...] lei superior, que vincula o Parlamento, e que não pode ser alterada por uma maioria regular do Parlamento, ou se é este Parlamento - isto é, a sua maioria - o supremo e soberano criador de leis" (LijPHART, 2003, p.247), dado que, ainda que seja o Executivo quem propõe a reforma, esta é debatida (e aprovada) no Legislativo. A questão da revisão judicial é importante para se verificar qual é a última instância - ou quais são as últimas instâncias - de declaração da constitucionalidade ou inconstitucionalidade das leis. Novamente a explicação para esse argumento está relacionada à questão da democracia representativa: os representantes do povo devem decidir acerca da constitucionalidade das leis ou esta é competência de um corpo judicial especializado nomeado e, freqüentemente, não representativo?

Considerações acerca da flexibilidade constitucional, dinâmica de formação das leis e revisão judicial

As Constituições dos três países aqui analisados passaram por reformas significativas, conforme Quadro 1, no qual se apontam também os atores responsáveis pela revisão judicial.

Lijphart (2003) divide a rigidez constitucional em dois grandes grupos: a) maiorias ordinárias; e b) maiorias maiores que as ordinárias. Estas subdividem-se em aprovação por maioria de dois terços; aprovação por menos de dois terços, mas mais que uma maioria comum; e aprovação por uma maioria maior que dois terços. Os índices crescentes de rigidez constitucional são, respectivamente: 1 para maiorias ordinárias; 2 entre dois terços e maiorias ordinárias; 3 para maiorias de dois terços; e 4 para supermaiorias, ou seja, acima de dois terços. Algumas considerações acerca de

Quadro 1: Países, reformas constitucionais e atores da revisão judicial

\begin{tabular}{|l|l|l|}
\hline País & Constituição & Revisão judicial \\
\hline Argentina & $\begin{array}{l}\text { Constituição de 1853; } \\
\text { reforma de 1994 }\end{array}$ & Na Suprema Corte \\
\hline Brasil & $\begin{array}{l}\text { Constituição de 1988; } \\
\text { reforma de 1998 }\end{array}$ & No Supremo Tribunal Federal \\
\hline Uruguai & $\begin{array}{l}\text { Constituição de 1967, com } \\
\text { reformas até 1996 }\end{array}$ & Na Corte Suprema \\
\hline
\end{tabular}

Fonte: PNUD, informe 2004. 
outras dinâmicas de formação das leis serão tecidas quando necessário.

Diferentemente da proposta feita por Lijphart (2003) para o estudo da questão da revisão judicial, não se abordará a questão do ativismo judicial para classificação da atuação do Judiciário. Com o objetivo de estabelecer maior relação entre reformas constitucionais, revisão judicial e reformas pró-mercado nos países estudados, este artigo identificará os mecanismos de revisão judicial, dando também ênfase em como são compostas as Cortes Constitucionais ou as Supremas Cortes. Buscar-se-á identificar se as cortes são corpos políticos totalmente independentes dos demais poderes ou se elas são constrangidas a agir de forma cooperativa com os demais poderes. Para isso, adotar-se-á o seguinte modelo para verificação nos níveis de revisão judicial: 1) revisão judicial difusa; 2) Suprema Corte independente, composta por membros indicados na sua totalidade pelo Executivo; 3) Suprema Corte independente, com composição mista - membros indicados pelo Executivo, Legislativo e/ou outras organizações sociais; 4) Tribunal Constitucional independente.

As subseções seguintes apresentarão análises do contexto institucional, dando ênfase às questões da flexibilidade constitucional e da revisão judicial em que as reformas pró-mercado foram - em alguns casos ainda são - implementadas no Brasil, na Argentina e no Uruguai.

\section{Reforma constitucional e revisão} judicial no Brasil, na Argentina e no Uruguai

\section{O caso brasileiro}

A reforma pró-mercado no Brasil e, mais amplamente, as reformas de Estado consistiram - e ainda consistem - em intensos debates. Os interesses dos atores políticos envolvidos em cada uma das reformas destacadas como prioritárias flexibilização de monopólios, previdência social, tributária, política - são muito intensos e, apesar de, no Brasil, as políticas para o mercado terem-se iniciado no governo de Fernando Collor de Mello (1990-1992), o plano de reforma do Estado foi desenvolvido no primeiro governo de Fernando Henrique Cardoso (1995-1998), quando foi criado o Mare (Ministério do Aparelho de Reforma do Estado). No segundo governo FHC (1999-2002), esse ministério foi extinto e as questões de reforma do Estado passaram a fazer parte do Ministério de Planejamento, Orçamento e Gestão.

No Brasil, a implementação de políticas de reforma do Estado, necessariamente, implica mudanças constitucionais. As emendas constitucionais - conforme estabelecido no art. 60 da Constituição Federal de 1988 - podem ser propostas por um terço, no mínimo, dos membros da Câmara dos Deputados ou do Senado Federal; pelo Presidente da República; ou por mais da metade das Assembléias Legislativas das unidades da Federação, se cada uma delas se manifestar pela maioria relativa de seus membros, sendo o Executivo o único ator que pode solicitar urgência para apreciação de projeto de sua iniciativa. Ressalta-se, portanto, a prevalência política do Executivo sobre os demais atores citados para o processo da aprovação das políticas.

Tendo o Executivo sido o propositor de todas as políticas de reforma do Estado no Brasil, os grandes debates acerca das mudanças constitucionais trazidas por essas políticas se dão no Congresso: as emendas constitucionais só podem ser implementadas se discutidas e votadas em cada casa 
do Congresso, em dois turnos, e se obtiverem três quintos dos votos dos respectivos membros. Essa regra, isolada da questão da revisão judicial, coloca o Brasil como um país em índice 2, de acordo com o modelo classificatório mencionado de Lijphart (2003).

O Brasil não possui um corpo judicial especializado somente para apreciação da constitucionalidade das leis, todavia, ainda durante a tramitação do projeto de lei, ela é apreciada na Comissão de Constituição, Justiça e Cidadania. É de competência dessa comissão opinar sobre a constitucionalidade, juridicidade e regimentalidade das matérias que lhe forem submetidas por deliberação do Plenário, por despacho da Presidência, por consulta de qualquer comissão ou quando, em virtude desses aspectos, houver recurso de decisão terminativa de comissão para o Plenário. O Regimento Interno do Senado Federal traz o seguinte texto em seu art. 101:

\section{$[\ldots]$}

$\S 1^{\circ}$ Quando a Comissão emitir parecer pela inconstitucionalidade e injuridicidade de qualquer proposição, será esta considerada rejeitada e arquivada definitivamente, por despacho do Presidente do Senado, salvo, não sendo unânime o parecer, recurso interposto nos termos do art. 254.

$\S 2^{\circ}$ Tratando-se de inconstitucionalidade parcial, a Comissão poderá oferecer emenda corrigindo o vício.

Importante ressaltar que o art. 254 traz em seu texto que, quando os projetos receberem pareceres contrários, quanto ao mérito, serão tidos como rejeitados e arquivados definitivamente, salvo recurso de um décimo dos membros do Senado no sentido de sua tramitação. A atuação dos senadores é, portanto, expressiva com relação à constitucionalidade das leis já em seu processo de tramitação. Ainda na tramitação da lei, o presidente da República, conforme o art. $66, \S 1^{\circ}$, da Constituição brasileira, pode vetar o projeto total ou parcialmente para prevalecer a constitucionalidade da lei.

Uma vez vigente a lei, sua inconstitucionalidade poderá ser declarada pelo presidente da República, pela Mesa do Senado Federal, pela Mesa da Câmara dos Deputados, pelo Procurador-Geral da República, pelos governadores de Estado, pelo Conselho Federal da Ordem dos Advogados do Brasil, por partido político com representação no Congresso Nacional e por confederação sindical ou entidade de classe de âmbito nacional. A Ação Direta de Inconstitucionalidade (ADIN) será processada e julgada pelo Supremo Tribunal Federal (STF). Após a declaração de inconstitucionalidade total ou parcial de lei pelo STF, o Senado Federal formulará, por meio da CCJ, projeto de resolução suspendendo a execução da lei no todo ou em parte. O STF é composto por 11 ministros nomeados pelo Executivo, depois de aprovada a escolha pela maioria do Senado.

A revisão judicial no Brasil não pode ser chamada concentrada uma vez que, para atuação do STF, é requerida declaração de inconstitucionalidade da lei por um dos atores políticos citados. Importante ressaltar que, com a exceção do Conselho Federal da $\mathrm{OAB}$ e das confederações sindicais ou entidades de classe de âmbito nacional, todos os outros atores com igual recurso de poder são representantes eleitos. Dessa forma, a questão da revisão judicial para a implementação de reforma do Estado no Brasil, quando negociada em 
torno de algum termo de constitucionalidade duvidosa, necessitará da estruturação de consenso, especialmente em se tratando de um corpo judiciário com forte apoio do Executivo. Com relação à classificação da revisão judicial, o Brasil se enquadra no índice 2 - ressalte-se que as atribuições dadas à Comissão de Constituição, Justiça e Cidadania, enquanto o projeto de lei ainda está sendo votado, poderia elevar um pouco esse índice.

\section{$\mathrm{O}$ caso argentino}

A Constituição argentina só pode ser modificada por iniciativa de dois terços dos membros do Congresso, cuja convocação será para o fim específico da alteração constitucional. Cabe ressaltar, no entanto, que essa mesma Constituição trata somente das declarações gerais constitucionais; direitos, garantias e deveres da pessoa; divisão política da nação; e da organização dos poderes. A Argentina se caracteriza pelo índice $3 \mathrm{da}$ classificação de Lijphart (2003). Grosso modo, a Constituição da Argentina não trata de todos os pontos das políticas abordadas pelas reformas de Estado (a título de exemplo, o regime econômico e financeiro do país): as reformas de Estado na Argentina são implementadas tanto por reformas constitucionais, como por legislação ordinária, dependendo da matéria. Dessa forma, dado que nem todas as políticas de reformas de Estado apresentam regime especial para sua aprovação, a questão da revisão judicial tornase ainda mais importante.

$\mathrm{Na}$ Argentina, são de responsabilidade da Corte Suprema e dos tribunais inferiores da Nação o conhecimento e a decisão de todas as causas que versem sobre pontos regidos pela Constituição (art. 116 da Constituição argentina). O sistema argen- tino respeita a regra do precedente, ou seja, os tribunais inferiores são obrigados a seguir a jurisprudência dos tribunais de maior hierarquia.

A revisão judicial na Argentina é difusa, ou seja, qualquer juiz possui a prerrogativa de contrastar uma norma com o texto constitucional e decidir acerca de sua constitucionalidade no caso concreto. Dessa forma, processos deliberativos complexos como os que conduzem à

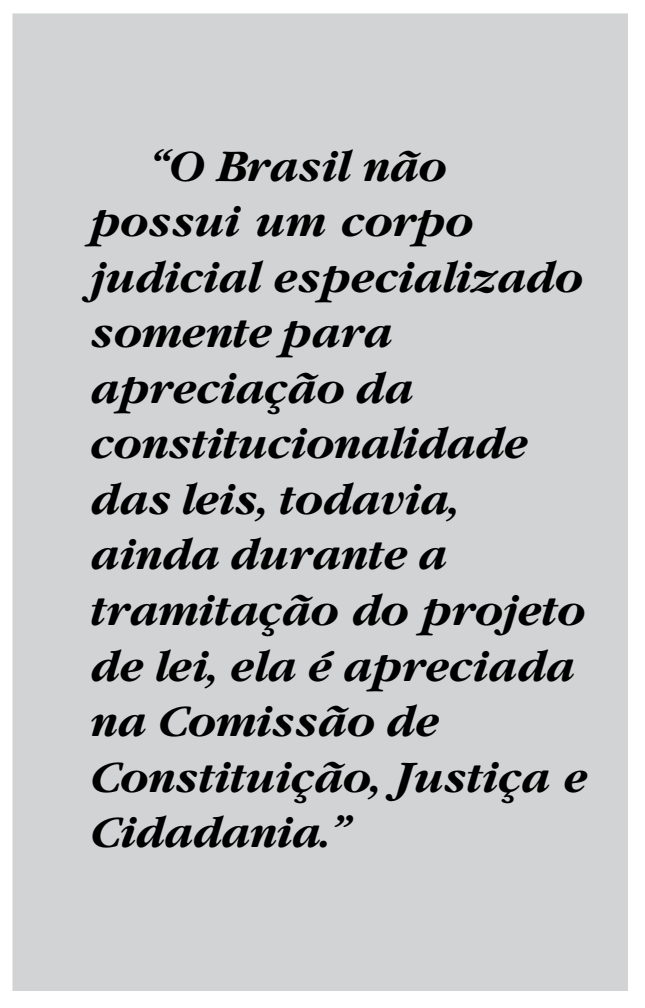

sanção de leis podem ser desconsiderados se o juiz tiver argumentos para sustentar que o resultado (lei ou norma sancionada) é contrário à Constituição. A decisão acerca da constitucionalidade das leis, todavia, só poderá ser tomada quando submetida a um caso concreto: não se pode declarar a inconstitucionalidade de uma norma em abstrato, sem que essa norma tenha afetado algum direito. Assim, só há duas formas 
de o sistema funcionar: se os cidadãos forem suficientemente educados jurídica e civicamente para atuar como agentes para a aplicação das leis; e se existirem os mecanismos processuais institucionalizados que viabilizem o acesso dos cidadãos à justiça. Grosso modo, os efeitos do controle de constitucionalidade só alcançam os casos concretos submetidos à consideração dos tribunais. Apesar de a Argentina possuir revisão judicial difusa, a existência da "regra do precedente", com uma Suprema Corte nomeada pelo presidente da $\mathrm{Nação}^{4}$, faz com que o país possua índice entre 1 e 2 .

\section{O caso uruguaio}

Os procedimentos de reforma da Constituição uruguaia são os mais distintos de todos os países aqui estudados. Os recursos de poder para iniciativa de proposta de emenda constitucional são distribuídos para diversos atores políticos - inclusive para os cidadãos -, sendo, na maioria das situações, requerido plebiscito.

A população, por iniciativa de $10 \%$ dos cidadãos, poderá apresentar projeto de resolução de emenda constitucional, que será submetido à decisão plebiscitária. A esse projeto podem ter sido apresentados projetos substitutivos pela Assembléia Geral, em reunião conjunta, os quais também passarão por decisão plebiscitária.

A Constituição ainda pode ser modificada pelos seguintes procedimentos: 1 ) por projetos de reforma que reúnam dois quintos do total de membros da Assembléia Geral, submetidos a plebiscito na primeira oportunidade que houver (neste caso, haverá plebiscito afirmativo se a maioria absoluta dos cidadãos que comparecerem a ele assim quiserem); 2) por projetos apresentados pelos senadores, pelos deputados ou pelo Poder Executivo, que deverão ser aprovados pela maioria absoluta dos membros da Assembléia Geral (neste caso, aprovada e promulgada a iniciativa pelo Presidente da Assembléia Geral, o Poder Executivo convocará, dentro de noventa dias, eleição para composição de uma Convenção Nacional Constituinte, com o dobro de parlamentares, que deliberará e resolverá sobre as iniciativas aprovadas para reforma. Os projetos, redigidos pela convenção e comunicados ao Poder Executivo para sua imediata publicação, deverão ser ratificados pelo Corpo Eleitoral, convocado pelo Executivo).

Diferentemente do caso chileno, no Uruguai o plebiscito é um mecanismo necessário em todos os casos de implementação de reformas constitucionais. Ele é um recurso que os grupos oponentes a determinada política têm para vetá-la. Segundo Kay (1999, p. 413),

"Grupos de interesse terão menos poder de veto em sistemas em que o Poder Executivo pode preceder o Congresso e introduzir legislação diretamente, como ocorre mais freqüentemente no uso dos decretos executivos do presidente Menem, do que em outros Executivos com poderes mais restritos (tradução nossa)" $"$.

Dessa forma, os procedimentos de reforma constitucional no Uruguai são rígidos, dando a este país 4 pontos de rigidez constitucional pela classificação de Lijphart (2003).

Para a preservação da constitucionalidade das leis, a Suprema Corte de Justiça é responsável pela declaração de sua inconstitucionalidade e da inaplicabilidade das disposições relativas a elas. Segundo o art. 258 da Constituição 
uruguaia, qualquer pessoa lesada por algum ato que considere inconstitucional poderá solicitar a declaração de inconstitucionalidade da lei pela Suprema Corte, seja por via de ação ou de exceção. Ressaltase, todavia, que a decisão da Suprema Corte só se refere ao caso concreto, não tendo, portanto, aplicabilidade em outros casos ou declaração permanente de inconstitucionalidade. A Suprema Corte uruguaia é composta por cinco membros, todos designados por maioria qualificada da Assembléia Geral. Ao Uruguai atribuímos o índice 1, pela sua revisão judicial difusa. Note-se que os procedimentos de reforma constitucionais estão muito pautados na decisão populacional e na consideração, portanto, de que a decisão da população e de seus representantes poderá alterar instituições anteriormente vigentes.

O art. 331 da Constituição uruguaia esclarece as condições para as reformas constitucionais e o plebiscito: "[...] se requerirá que vote 'SI' la mayoria absoluta de los ciudadanos que concurram a los comicios, la que debe representar por lo menos, el 35\% del total de inscriptos en el Registro Cívico Nacional".

Classificação da rigidez constitucional $x$ revisão judicial na Argentina, no Brasil e no Uruguai

Grosso modo, segundo Lijphart (2003, p. 259), tanto a rigidez constitucional quanto a revisão judicial são recursos antimajoritários. Forte revisão judicial, sem contar com rigidez constitucional, pode facilmente ser revista por uma proposta de emenda constitucional, feita por parlamentares ou pelo Executivo. Da mesma forma, fraca revisão judicial, mas Constituição rígida implica que a maioria parlamentar - no caso uruguaio não só os parlamentares, mas também a população - teria maior probabilidade de implementar uma lei constitucionalmente questionável, caso assim optasse, por meio dos procedimentos lícitos.

O Quadro 2 indica como os órgãos responsáveis pela revisão judicial (Corte Suprema na Argentina, no Brasil e no Uruguai) são compostos, e a Figura 1 posiciona os três países em relação à rigidez constitucional e à revisão judicial.

\section{Reformas previdenciárias no Brasil, na Argentina e no Uruguai}

As reformas previdenciárias foram escolhidas como exemplo para se tratar da rigidez constitucional e da revisão judicial de reformas pró-mercado pelos seguintes motivos: 1) as reformas previdenciárias são ao mesmo tempo reformas constitucionais $^{6}$ e reformas pró-mercado; 2) de maneira geral, o rearranjo de políticas redistributivas altera padrões de benefícios, fomentando, assim, o jogo político e permitindo análise mais acurada dos casos. Dessa forma, as reformas previdenciárias são operacionalizadas de forma que os recursos de poder dos atores do Executivo, do Legislativo e do Judiciário (especialmente no concernente às Supremas Cortes e aos Tribunais Constitucionais), bem como de setores específicos da sociedade, são altamente mobilizados. Procuraremos, portanto, enfatizar as questões tratadas anteriormente para os casos das reformas da previdência nos países citados.

\section{A reforma previdenciária no Brasil}

A reforma da previdência social no Brasil foi marcada por ter-se dividido em dois momentos: um processo de reforma no governo FHC e outro no governo Lula. A reforma previdenciária, além de 
Quadro 2: A composição dos órgãos responsáveis pela revisão judicial

\begin{tabular}{|l|l|l|l|}
\hline Argentina & $\begin{array}{l}\text { O presidente indica o } \\
\text { candidato }\end{array}$ & $\begin{array}{l}\text { O Senado aprova por } \\
\text { dois terços }\end{array}$ & $\begin{array}{l}\text { Cargo vitalício (aposen- } \\
\text { tadoria obrigatória os } \\
75 \text { anos) }\end{array}$ \\
\hline Brasil & $\begin{array}{l}\text { O presidente indica o } \\
\text { candidato }\end{array}$ & $\begin{array}{l}\text { O Senado aprova por } \\
\text { maioria absoluta }\end{array}$ & $\begin{array}{l}\text { Cargo vitalício (aposen- } \\
\text { tadoria obrigatória aos } \\
70 \text { anos) }\end{array}$ \\
\hline Uruguai & $\begin{array}{l}\text { O Congresso seleciona } \\
\text { os candidatos }\end{array}$ & $\begin{array}{l}\text { AAssembléia Geral } \\
\text { (as duas casas do } \\
\text { Congresso) escolhe os } \\
\text { candidatos por dois } \\
\text { terços dos votos }\end{array}$ & $\begin{array}{l}\text { Ocupam o cargo por 10 } \\
\text { anos podendo ser } \\
\text { reeleito por mais 5 anos } \\
\text { (aposentadoria obriga- } \\
\text { tória aos 70 anos) }\end{array}$ \\
\hline
\end{tabular}

Fonte: PNUD, informe 2004.

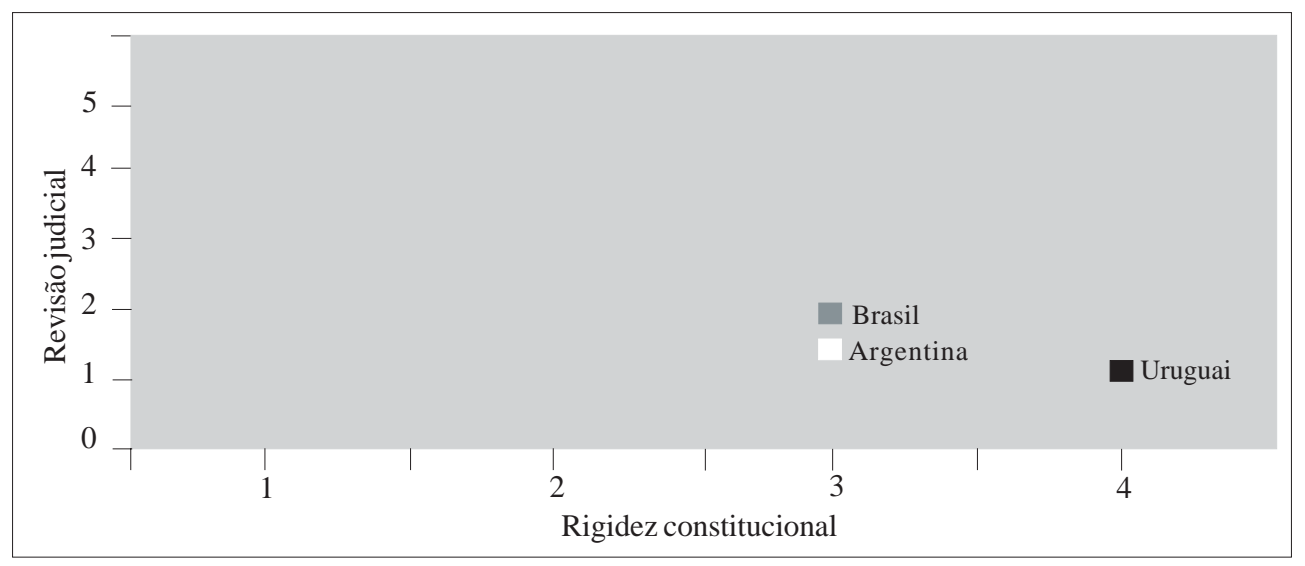

Figura 1: Posição do Brasil, da Argentina e do Uruguai em relação à rigidez constitucional e à revisão judicial

apresentar grandes modificações nos direitos dos beneficiários, só pode ser implementada por meio de emenda constitucional. Uma vez que a Constituição brasileira requer três quintos dos votos dos membros do Congresso para aprovação da proposta de emenda, o desenvolvimento de maior consenso para implementação da reforma torna-se ainda maior, pela dispersão tanto de interesses quanto de poderes, que dá origem aos diversos veto players.
No governo FHC, a PEC no 33 foi enviada ao Congresso em 1995. Apesar de ter sido aprovada na Câmara dos Deputados, foi substituída pela PEC no 40 , enviada pelo governo Lula. Uma vez que emendas constitucionais são difíceis de ser implementadas, pela maior rigidez constitucional com relação às demais leis ordinárias e complementares, os atores políticos lançam mão de outros instrumentos institucionais para facilitar a implementação 
do desenho institucional mais desejado por eles. No governo FHC, a oposição lançou mão dos Destaque para Votação em Separado (DVS). Segundo Anastasia e Melo (2004, p. 13),

"[...] os partidos oposicionistas podem destacar partes do texto aprovado e obrigar o governo a expor sua base em votações polêmicas. Como cabe ao Executivo confirmar a maioria qualificada, aumentam as chances de sucesso da oposição, que passa a necessitar do primeiro número maior que dois quintos dos votos para exercer seu poder de veto".

Como no próprio governo FHC o número de DVS por partido foi limitado, essa alteração regimental beneficiou o governo Lula e tornou-se crucial para a votação e aprovação da reforma. Outro fator essencial para se entender a reforma da previdência no governo FHC e no governo Lula foi a alteração do comportamento dos congressistas: "[...] a troca de lugares entre oposição e situação, acarretou uma mudança na distribuição das preferências e dos recursos entre os atores [...]" (Anastasia; Melo, 2004). Tanto no Brasil quanto no Uruguai, os movimentos dos aposentados e as confederações sindicais formaram coalizões com os partidos de esquerda na intenção de bloquear os termos das reformas previdenciárias. Além desses atores, as organizações empresariais no Brasil não chegaram a acordos bem estruturados, transferindo, dessa forma, suas intenções ao Ministério do Planejamento, Orçamento e Gestão, ou seja, ao Executivo.

A rigidez constitucional também opera no sentido de fazer com que o governo negocie com a oposição, para garantir a implementação de políticas de preferências intensas. O PSDB, também por questão de preferências intensas, não se comportou como oposição pelo simples fato de sempre ter apoiado a reforma da previdência como programa partidário e política de governo. Foi coerente com sua história e mediu os "custos de se opor por se opor", embora não tenha alcançado total adesão de seus parlamentares.

Importante ressaltar que, dado o alto grau de desconstitucionalização das políticas implementadas pela reforma previdenciária, recaem ao Judiciário importantes decisões. No caso brasileiro, o Supremo Tribunal Federal foi acionado para decidir acerca da constitucionalidade da cobrança previdenciária dos servidores inativos e de pensionistas. O governo conseguiu - por sete votos a favor e quatro contra - manter a cobrança. Entretanto, um fato questionável é o da legitimidade do ativismo do Supremo Tribunal Federal neste caso, que optou pela elevação do teto da isenção da cobrança ${ }^{7}$, atuando não só como Judiciário, mas também como Legislativo. As ADINs foram movidas pela Associação Nacional dos Membros do Ministério Público (Conamp) e pela Associação Nacional dos Procuradores da República, e a declaração de sua constitucionalidade, com a redução implementada pelo STF, representou forte intervenção do Judiciário.

\section{A reforma previdenciária na Argentina}

A Argentina possuía regimes de previdência distintos: “(...) muitas províncias possuíam um sistema de aposentadorias para os funcionários públicos locais, os funcionários públicos federais tinham outro, havia regimes diferenciados para juízes, militares e legisladores" (Folha de S.Paulo, 19/1/2003). 
A Argentina caracteriza-se por alta rigidez constitucional, baixa revisão judicial e, com relação à questão previdenciária, grande dissenso dentro do Executivo. Dessa forma, dois seriam os esforços naturais para a aprovação da reforma: o primeiro, para criar maior consenso no Executivo e o segundo, para garantir dois terços de votos no Congresso. Ou seja, a alta rigidez constitucional requeria a cooperação de diversos atores. Uma das estratégias adotadas pelo ministro Cavallo para ampliação de consenso acerca da reforma da previdência no Executivo foi a de subordinação da área da seguridade social pela gestão macroeconômica. Para tal, um grupo de técnicos de sua confiança - que na gestão Alfosin (1984- 1989) assessorara o Ministério da Economia - ocupou a Secretaria de Seguridade Social, assumida por Walter Schulthess. Segundo Coelho (2001), "Com isso, os 'velhos' atores, que eram contra as reformas estruturais, praticamente desapareceram da cena".

O projeto de reforma da previdência argentina foi enviado ao Congresso em 1991 e em 1993. Depois de longa negociação entre o Executivo e o Legislativo, estabeleceram-se três alternativas aos trabalhadores argentinos:

"[...] um sistema público de repartição, um sistema misto em que o componente de capitalização ficaria sob administração estatal - Administradora de Fondos de Jubilaciones y Pensiones (AFJP) -, e um outro sistema misto em que o componente capitalização seria administrado por agências privadas" (CoElHo, 2001).

Apesar de algumas definições terem sido realizadas no Congresso, certos pontos da reforma foram determinados de maneira distinta, para evitar os entraves da rigidez constitucional e da revisão judicial. O presidente Menem lançou mão de uma de suas atribuições, qual seja, a de ditar decretos. Grosso modo, os decretos devem ser utilizados em casos excepcionais, por razões de necessidade e urgência, que serão decididos em acordo geral de ministros, os quais deverão referendá-los, juntamente com o chefe de gabinete de ministros. Dessa forma, um Judiciário independente teria sua atuação fortemente demandada, para checar tanto a constitucionalidade dos decretos quanto as matérias neles abordadas. Kay (1999, p. 415) aponta-nos uma estratégia utilizada pelo governo Menem para eliminação de um veto player.

"[...] Argentine president Menem broadened the power of the executive by enlarging the supreme court and appointing political allies as justices, making frequent use of the partial veto, and, most important for social security reform, using the emergency executive decree for ordinary legislation".

Larkins (1998, p. 434) complementa afirmando que "In sum, the decree represented an extremely questionable grant of power to the Executive to take on legislative functions and suspend certain constitutional rights". Enquanto no Brasil o Judiciário permaneceu mais independente e o presidente contava com um veto player para implementação de medidas provisórias, na Argentina o Judiciário também estava, com o Executivo, mais preocupado com a implementação de algumas questões do que com sua própria constitucionalidade.

\section{A reforma previdenciária no}

\section{Uruguai}

Em 1989, um movimento de protesto dos aposentados uruguaios contra a deterioração de seus vencimentos 
culminou em um plebiscito e na mudança das regras constitucionais para o cálculo e reajuste dos benefícios. Além de ser financeiramente insustentável, o sistema sofria com ineficiências administrativas que somente aumentavam seus custos. Todavia, um posterior déficit de $5,2 \%$ na previdência social em 1994 teve como conseqüência o envio de diversos projetos de reforma ao Congresso, que não obtiveram êxito. Desde então, o Executivo, por meio do Ministério da Economia e de incentivos financeiros do BID, começou a ganhar espaço para o desenho das novas instituições políticas da previdência social. O Executivo uruguaio também teve de melhor estruturar-se para conseguir consistência em suas proposições e viabilizar a reforma por meio de coalizões, dada a alta rigidez constitucional. O presidente Sanguinetti - do Partido Colorado - ao contrário do governo Lacalle, conseguiu coordenar as diversas disputas dentro do próprio Executivo, o que garantiu melhor a construção de consenso para negociação com os membros da coalizão. O Partido Colorado, apenas com $24 \%$ das cadeiras do Congresso, foi obrigado a reforçar a coalizão com o Partido Blanco ${ }^{8}$, bem como a ceder em alguns pontos, para a manutenção da coalizão. Durante o processo de elaboração do projeto de reforma, os políticos da coalizão detiveram cargos de mando no Executivo.

Segundo Coelho (2001),

"[...] a força dos atores políticos no interior do Executivo contribui para promover uma reforma muito menos radical do que fariam supor a debilidade de sua burocracia previdenciária, a magnitude do déficit e mesmo as condições favoráveis para financiar os custos de transição".
Em março de 1996, o Parlamento uruguaio aprovou a lei da reforma do sistema e rapidamente $86 \%$ dos trabalhadores elegíveis aderiram ao novo plano voluntariamente. Um momento chave na batalha pela opinião pública veio na forma de tentativa de convocar um plebiscito contra a reforma. Quando os organizadores não conseguiram recolher o número necessário de assinaturas, ficou claro que a oposição à reforma proposta não era forte o suficiente para tirá-la dos trilhos. Oscar Bottinelli, diretor da Factum, uma agência de pesquisa de opinião pública do Uruguai, disse que o percentual da população contrária à reforma era ligeiramente mais alta do que aquela a favor, mas que uma grande proporção permaneceu indecisa.

Além de poder estruturar-se para a proposição das demais reformas prómercado, o Executivo tem iniciativa privativa em matérias de seguridade social. Outro fator importantíssimo para o estudo da reforma da previdência no Uruguai é que ela dependia somente de maioria simples no Congresso, uma vez que os cidadãos atuam fortemente por meio de plebiscitos, dos quais vem a altíssima rigidez da Constituição uruguaia.

Com relação à questão da revisão judicial, a Constituição uruguaia estabeleceu uma exceção, nas disposições transitórias e especiais (art. 332), para lidar com a reforma previdenciária:

"V - Sin perjuicio de lo establecido en los articulos 216 y 256 y siguientes de la Constitución de la República, declárase la inconstitucionalidad de toda modificación de seguridad social, seguros sociales, o previsión social (articulo n $n^{\circ}$ 67) que se contenga en leyes presupuestales o de rendición de cuentas, a 
partir del $1^{\circ}$ de octubre de 1992. La Suprema Corte de Justicia, de oficio, o a petición de cualquier habitante de la República, emitirá pronunciamiento sin más trámite, indicando las normas a las que debe aplicarse esta declaración, lo que comunicará al Poder Ejecutivo y al Poder Legislativo. Dichas normas dejarán de producir efecto para todos los casos, y con retroactividad a su vigencia".

O modelo de previdência uruguaio hoje está estruturado em um sistema híbrido, ou misto, baseado na poupança pessoal - os trabalhadores têm suas próprias contas e sabem o quanto depositaram nelas - com o princípio de solidariedade e benefícios públicos. O Banco da Previdência do Uruguai administra um pacote básico de benefícios aos cidadãos, enquanto empresas públicas e privadas de fundos de pensão administram contas individuais. Os contribuintes podem escolher qual dessas companhias administrará suas contas.

\section{Conclusão}

Ao se tratar de reformas pró-mercado em perspectiva comparada, uma questão importante a ser determinada é qual o escopo institucional que molda e constrange as preferências dos atores políticos ${ }^{9}$. Este artigo objetivou mostrar que as instituições constitucionais são de extrema importância no movimento dos atores para a implementação de reformas pró-mercado, em um regime democrático. Estudar os veto players institucionais das reformas constitucionais fornece uma explicação de como as instituições criam oportunidades para os diversos grupos de interesses participarem da formulação da política.

Os regimes democráticos respeitam as expectativas dos atores sobre a ocorrência de jogo político para a implementação das preferências. Se o regime é democrático, pelas vias da representação, sabe-se que as negociações entre os poderes constituintes do Estado e a sociedade se darão em esferas públicas e que, muito dificilmente, a proposta de reforma inicial será a proposta finalmente aprovada. Ou seja, na arena de debate, os atores políticos agirão ora cooperativamente, ora competitivamente.

A rigidez constitucional e a existência de revisão constitucional são determinantes para a maior necessidade de criação de consenso acerca de uma determinada opção de política. No Brasil, as reformas pró-mercado vêm sendo marcadas por características de um país em que há forte revisão constitucional. A reforma previdenciária foi marcada pela mobilização da sociedade civil e pelo ativismo tanto do Executivo e Legislativo quanto do Judiciário. A estratégia utilizada no Brasil para a viabilização da aprovação da reforma no Legislativo foi a de formação de coalizões, sendo que, ainda assim, foram necessários dois momentos distintos para que a reforma pudesse ser implementada. A proposta do Executivo foi diversamente modificada, das quais três grandes foram realizadas pela existência de revisão judicial no processo legislativo: a Comissão de Constituição e Justiça. O país presenciou, ainda, forte ativismo do Judiciário, quando o Supremo Tribunal Federal, ao declarar a constitucionalidade da cobrança dos inativos e aumentar o teto para isenção destes, atuou como legislador.

Enquanto no Brasil os diversos oponentes à implementação de um sistema privatizado de previdência contaram com $\mathrm{o}$ alto preço de requerer votos de maioria qualificada nas duas casas legislativas, no Uruguai os oponentes a esse sistema 
lançaram mão do plebiscito. A análise de Busquets (2000) aponta o Uruguai como um país onde os recursos de poder são mais distribuídos, em comparação ao Chile, por exemplo. Esses recursos proporcionaram uma análise em que fatores como a alta força da oposição no Congresso, o alto poder legislativo do presidente e a pathdependence propiciaram, como resultado, um modelo de previdência misto. Comparando-se com a Argentina, no entanto, que também tem um modelo misto de previdência social, a "tabla de la verdad" de Busquets não aponta os mesmos recursos de poder nesse país confirmando, assim, que é possível encontrar diferentes combinações causais (suas hipóteses), que levam a resultados iguais, do mesmo modo que é provável que combinações iguais cheguem a resultados diferentes. Esse argumento estaria relacionado, portanto, a estratégias que os atores utilizam para implementar as reformas: as estratégias são diferentes para arranjos institucionais distintos, como se procurou mostrar, podendo levar, de tal forma, a resultados similares. Ressalte-se, contudo, que, para alcançar resultados similares em contextos institucionais distintos, os jogos políticos também devem ser distintos, corroborando, assim, o argumento neo institucionalista do constrangimento das ações políticas dos atores pelas instituições.

O conceito de democracia delegativa desenvolvido por O’Donnell para tratar das democracias latino-americanas pode ser mais bem visualizado no caso argentino. Democracia delegativa é definida como um modelo de democracia no qual quem define os interesses da sociedade é o governo democraticamente eleito, sendo as políticas, muitas vezes, implementadas em um modelo top-down. Para enfrentar as barreiras de modificação de uma Constituição rígida, o governo
Menem optou por implementar a reforma previdenciária passando uma parte dela pelo Legislativo e outra pelo Judiciário, ou seja, pela revisão judicial. Sabendo que o Legislativo é um corpo em que diversos interesses possuem recursos de poder, com a implementação de uma reforma estrutural por decretos executivos, em contexto em que o Judiciário não representa mais um veto player, o governo Menem objetivou

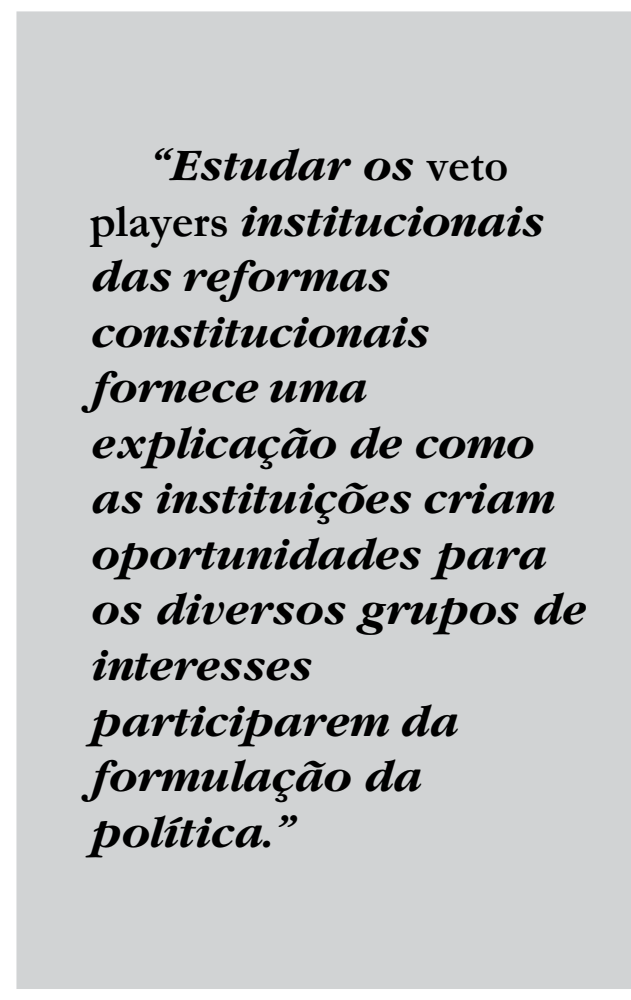

reduzir os impactos tanto da rigidez constitucional, quanto da revisão judicial para a implementação da reforma previdenciária na Argentina. Nesse sentido, os oponentes de um regime privatizado tiveram demasiada dificuldade em achar mecanismos institucionalizados para agir como veto players, uma vez que o Executivo, além de deter superpoderes, tinha muitos aliados na Suprema Corte. 
Nesse sentido, argumenta-se também que, apesar de a revisão judicial ser uma questão que objetiva garantir a constitucionalidade das leis, não são somente os atributos das cortes supremas ou cortes constitucionais que importam, mas também sua independência dos demais poderes, inclusive com relação ao processo de nomeação.
Tentou-se mostrar ainda que, nos países estudados, o Executivo foi o ator que iniciou as reformas, dado seus recursos de poder constitucionais, o que influenciou incisivamente na adoção de modelos bem liberalizantes de previdência social.

(Artigo recebido em maio de 2005. Versão final em junho de 2006)

\section{Notas}

${ }^{1}$ Segundo Tsebelis (1998), política de mudança institucional pode envolver uma ou mais das seguintes opções: 1) uma mudança no conjunto de jogadores; 2) uma mudança nas jogadas permitidas; 3) uma mudança na seqüência do jogo; 4) uma mudança na avaliação disponível.

${ }^{2}$ Veto player é um ator político de cuja decisão depende a aprovação ou rejeição de determinada política. Esses atores podem ser tanto institucionais

- como é o caso do Judiciário

- quanto não institucionais, mas conjunturais

- como é o caso de partidos políticos.

${ }^{3}$ No caso latino-americano, a crise não foi atribuída a amplos programas sociais, embora Azevedo (1997) aponte o Uruguai como exceção a essa regra, especialmente nos anos 60, quando o país chegou a ser chamado de a "Suíça latino-americana".

${ }^{4}$ Com acordo do Senado por dois terços de seus membros.

5 "Interest groups will have less veto power in systems where the executive branch can bypass the congress and directly introduce legislation, as in president Menem's frequent use of emergency executive decrees, than in ones where executive powers are more restricted".

${ }^{6}$ Sejam essas alterações parcialmente ou totalmente constitucionais.

${ }^{7}$ A elevação do teto da cobrança, apesar de desejada pelo Executivo, impacta em redução de $24 \%$ do esperado.

${ }^{8}$ Partido de orientação neoliberal, responsável pela implementação da primeira reforma previdenciária.

${ }^{9} \mathrm{O}$ termo constrange é utilizado no sentido da existência de instituições que proíbem ou determinam certos movimentos. 


\section{Referências bibliográficas}

Anastasia, Fátima; Melo, Carlos Ranulfo. Accountability, representação e estabilidade política no Brasil, 2002.

. A reforma da previdência em dois tempos. In: ENCONTRO ABCP 2004.

. Democracia e representação no Cone Sul (no prelo).

Argelina, C. Figueiredo; Limongi, Fernando. Reforma da previdência e instituições políticas. Novos Estudos CEBRAP, n. 50, 1998.

Argentina. Constitución de 1994. Disponivel em: <http://www.georgetown.edu/ pdba/Constitutions/Argentina/argentina.html>.

Boschi, Renato. Instituições políticas, reformas estruturais e cidadania: dilemas da democracia no Brasil. Mimeografado.

Sintesis, 1995.

Democratizacion y reestruturacion del sector privado en America Latina.

Boschi, Renato; DinIz, Eli; SANTos, Fabiano. Elites políticas e econômicas no Brasil contemporâneo. Rio de Janeiro: Fundação Konrad Adenauer, 2000

Empresários, reformas institucionais e representação de interesses: dilemas do desenvolvimento no Brasil (no prelo). Introdução, cap. 1, 2, 3, 4, conclusão.

Brasil. Constituição da República Federativa do Brasil. Promulgada em 5 de outubro de 1988. Disponível em: <http://www.senado.gov.br>.

BusQueTs, José Miguel. Las reformas de la seguridad social en Argentina, Bolívia, Chile e Uruguai (1981-1995). Paper prepared for the 2000 meeting of the Latin America Studies Association, Hyatt Regency, March 16-18, 2000.

PEC 029/2000. Disponível em: <http://www.senado.gov.br.

Chile. Constituição de 1980 com reformas até 2003. Disponível em: <http:// www.georgetown.edu/pdba/Constitutions/Chile/chile.html>.

Coelho, Vera Schattan P. Poder Executivo e reforma da previdência na América Latina. Novos Estudos, n. 21, nov. 2001.

- A reforma da previdência e o jogo político no interior do Executivo.

Novos Estudos, n. 55, nov. 1999.

Diniz, Eli; Azevedo, Sérgio (Org.). Reforma do Estado e democracia no Brasil: dilemas e perspectivas. Brasilia: Ed. UnB; ENAP, 1997.

DinIZ, Eli. Governabilidade, governança e reforma do Estado: considerações sobre o novo paradigma. Revista do Serviço Público, Brasília, ano 47, n. 2, p. 05-21, maio-ago. 1996.

KAY, Stephen J. Unexpected privatizations: politics and social security reform in the Southern Cone. Comparative Politics, v. 31, n. 4, July 1999.

LARKINS, Christopher. The Judiciary and delegative democracy in Argentina. Comparative Politics, v. 30, n. 4. July 1998. 
LjpHART, Arend. Modelos de democracia: desempenho e padrões de governo em 36 democracias. Rio de Janeiro: Civilização Brasileira, 2003.

Manin, Bernard. As metamorfoses do governo representativo, RBCS, n. 29, 1995.

Marini, Caio. O contexto contemporâneo da administração pública na América Latina. Revista do Serviço Público, ano 53, n. 2, out.-dez. 2002.

Melo Filho, Hugo Cavalcanti. A reforma do Poder Judiciário brasileiro: motivações, quadro atual de perspectivas. CEJ, 2003.

NoRTH, Douglas C. Transaction costs, institutions and economic performance, v.30, Occasional pappers. International Centers for Economic Growth (IGEG).

ReIs, Fábio Wanderley. Governabilidade, instituições e partidos. Novos Estudos, São Paulo, n. 41, p. 40-60, mar. 1995

SOARES, Laura Tavares. Reforma da previdência na perspectiva social, 2003.

Tsebelis, George. Jogos Ocultos. São Paulo: Ed. USP, 1998.

Uruguai. Constitución de 1967, con reformas hasta 1996. Disponível em: <http:// www.georgetown.edu/pdba/Constitutions/Uruguay/uruguay.html>.

Informativo sobre reforma da previdência. Disponível em: $<$ http:// www.senado.gov.br>. Acesso: 24 ago. 2004.

Werneck Vianna, Luiz. A democracia e os Três Poderes no Brasil. Belo Horizonte: Ed. UFMG, 2002. 


\section{Resumo - Resumen - Abstract}

Reformas pró-mercado, rigidez constitucional e revisão judicial: Brasil, Argentina e Uruguai em perspectiva comparada

\section{Izabela Moreira Corrêa e Vanúzia Gonçalves Amaral}

Este artigo aborda a importância da distribuição de poderes de agenda e de veto dos cidadãos e dos Poderes Executivo, Legislativo e Judiciário para viabilizar a implementação de reformas prómercado no Brasil, na Argentina e no Uruguai em perspectiva comparada. Nesse sentido, o artigo aborda os temas da flexibilidade constitucional, da dinâmica de formação das leis e da presença ou ausência de revisão judicial. A hipótese subjacente a este artigo é a de que quanto mais rígida a Constituição - variável que envolve o poder de agenda e de veto dos cidadãos, do Executivo, do Legislativo e do Judiciário - mais bem desenhado deve ser o jogo político para a viabilização de implementação das reformas. Para exemplificar este artigo, foram analisadas as reformas previdenciárias implantadas nos países em estudo.

Palavras-chave: reformas pró-mercado; rigidez constitucional; revisão judicial.

Reformas pro-mercado, rigidez constitucional y revisión constitucional: Brasil, Argentina y Uruguay desde una perspectiva comparada

Izabela Moreira Corrêa y Vanúzia Gonçalves Amaral

Este artículo trata de la importancia de la distribución de los poderes de agenda y de veto de los ciudadanos y de los Poderes Ejecutivo, Legislativo y Judiciario para la viabilidad de la implementación de reformas "pro-mercado" en Brasil, Argentina y Uruguay desde una perspectiva comparada. En este sentido, el artículo aborda los temas de la flexibilidad constitucional, dinámica de formación de las leyes y la presencia o la ausencia de revisión judicial. La hipótesis subyacente a este artículo es la que, tanto más inflexible la Constitución - variable que envuelve el poder de agenda y de veto de los ciudadanos, Ejecutivo, Legislativo y Judiciario - mejor trazado debe ser el juego político para la viabilidad de implementación de las reformas. Para dar ejemplo en este artículo, fueron analizadas las reformas en la Seguridad Social implantadas en los países en estudio.

Palabras clave: reformas pro-mercado; flexibilidad constitucional; revisión judicial.

Pro-market reforms, constitutional rigidity and judicial review: Brazil, Argentina and Uruguay in comparative perspective

Izabela Moreira Corrêa and Vanúzia Gonçalves Amaral

This paper addresses the importance of the distribution of agenda and veto powers among citizens and the Executive, Legislative and Judiciary powers in order to allow the implementation of pro-market reforms in Brazil, Argentina and Uruguay. In comparative perspective, the paper deals with the issues of constitutional flexibility, law formation dynamics and the presence or absence of judicial review. The main hypothesis in this paper is that the harder it is for the Constitution to be altered, the harder it is to design the political game to implement reforms. The reforms of the social security systems implemented in Brazil, Argentina and Uruguay exemplified our analysis.

Key words: pro-market reforms; constitutional flexibility; judicial review. 
Izabela Moreira Corrêa

Diretora de Modernização da Secretaria de Estado de Saúde de Minas Gerais e mestre em Ciência Política pela Universidade Federal de Minas Gerais. Contato: <izabela.correa@terra.com.br>

Vanúzia Gonçalves Amaral

Servidora da Prefeitura de Belo Horizonte e mestranda em Ciência Política pela Universidade Federal de Minas Gerais. 